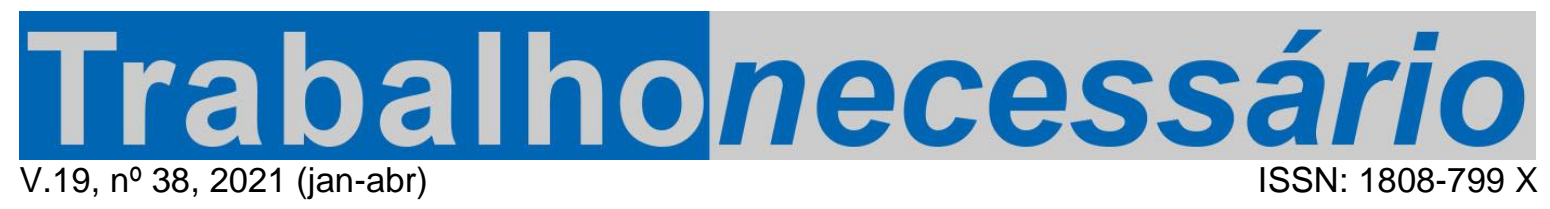

\title{
ESCUTA AS MANAS: A EXPERIÊNCIA E A CONSTRUÇÃO DA ARTE URBANA DE GÊNERO NO RIO DE JANEIRO'
}

Priscila Castro ${ }^{2}$

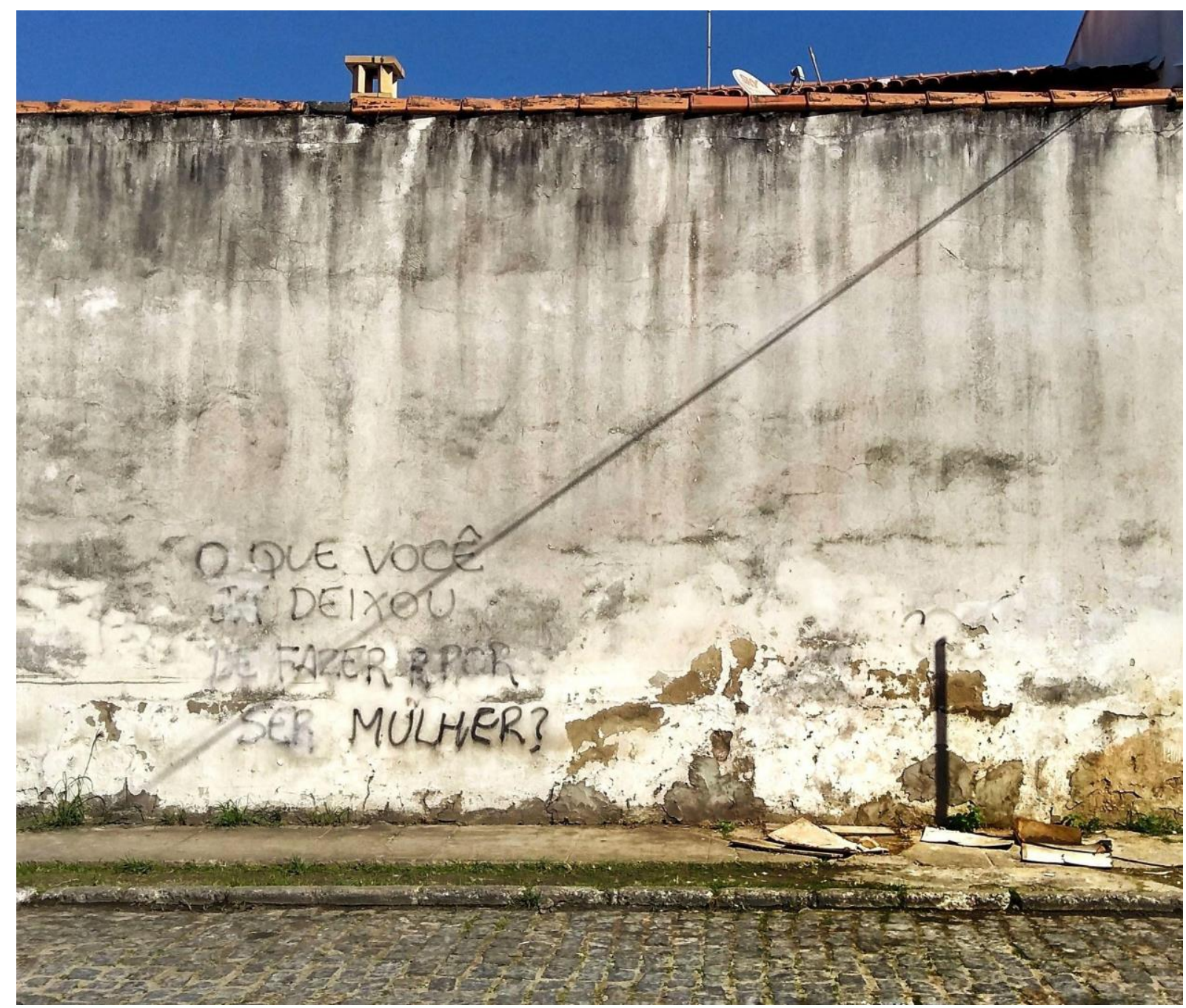

Foto: O que?

Autor: Priscila Castro, Rio das Ostras- RJ, junho de 2018.

1 Ensaio recebido em 16/09/2020. Aprovado pelos editores em 16/09/2020. Publicado em 25/02/2021. DOl: https://doi.org/10.22409/tn.v19i38.46220.

2 Doutora em Serviço Social pela Universidade do Estado do Rio de Janeiro - UERJ, Rio de Janeiro RJ, Brasil; Mestre em Serviço Social pela Universidade Federal de Juiz de Fora - UFJF, Minas Gerais - MG, Brasil; Especialista em Políticas Públicas pela Universidade Federal de Minas Gerais - UFMG, Minas Gerais - MG, Brasil; Graduada em Serviço Social pela UFJF - MG, Brasil; Assistente Social da Federação das Indústrias do Estado do Rio de Janeiro FIRJAN; E-mail: priscilardcastro@gmail.com; Lattes: http://lattes.cnpq.br/2203394196267866 e ORCID: 0000-0002-3288-5419 
Este ensaio pretende destacar a presença de mulheres na produção de graffitis na cidade do Rio de Janeiro, tendo como foco as possibilidades de conquista cotidiana do espaço público e consequentemente das implicações resultantes da ampliação das percepções político e pedagógicas da arte como instrumento das lutas feministas.

A arte é entendida aqui como componente essencial da sociabilidade humana e um importante campo para o estabelecimento de mediações teóricas e construção de conhecimento. Presente de forma concreta na vida dos sujeitos, ela se liga à essência humana: "o homem se eleva, se afirma, transformando a realidade, humanizando-a, e a arte com seus produtos satisfaz essa necessidade de humanização" (VÁZQUEZ, 2010, p.43). A arte carrega também as contradições advindas da base da produção econômica e suas relações sociais. Sofre, portanto, uma reconfiguração e tem sua função social distorcida no curso do desenvolvimento da história.

Este processo não se dá de forma mecânica: a arte e o desenvolvimento produtivo e econômico estabelecem relações que ganham contornos importantes no estágio do capitalismo tardio. As contradições que permeiam esse processo histórico de consolidação e dominação capitalista engendram, na mesma medida, forças e práticas de resistência que tensionam esta ordem. O capitalismo, nestes marcos, atualiza o obscurecimento das práticas artísticas contemporâneas, portanto, é necessário e urgente realizarmos análises críticas às manifestações e expressões artísticas populares no sentido de situar as tendências e possibilidades emancipatórias.

Analisar a arte urbana ${ }^{3}$ significa pensar a relação da cultura, espaço e os desdobramentos e implicações desta apropriação no sentido político da ação do sujeito artista. Pensando na diversidade das manifestações contidas nas definições de arte urbana, que muitas vezes não se enquadram nas manifestações artísticas ditas convencionais, e que geralmente são interpretadas como transgressões ou criminalizadas, cabe, dentro da perspectiva do direito à cidade desenvolvido por Lefebvre (2008) diferenciá-las e compreendê-las. Abarcando as interpretações sobre

\footnotetext{
${ }^{3}$ Podemos identificar como arte urbana ou street art todas as formas, tipos e estilos artísticos que acontecem essencialmente na rua, expostas nas cidades, em vias públicas e de grande circulação. As definições sobre o conceito são contraditórias e não consensuais. Porém, podemos indicar que se relaciona com características populares e lúdicas e os conteúdos dizem respeito as relações e vivências cotidianas dos sujeitos.
} 
o que seriam expressões de identidades, de modos de vida, de culturas, bem como reconhecer as potencialidades de representações e práticas com sustentação política.

Como parte dos resultados alcançados em pesquisa acadêmica ${ }^{4}$, devolvemos agora algumas reflexões e imagens capturadas durante a coleta de dados. O registro fotográfico foi um importante elemento metodológico de investigação, além de significar um caminho artístico redescoberto pela própria pesquisadora. Registramos algumas obras importantes na cidade, aproveitando os momentos pessoais de deslocamento e momentos da prática de graffiti feito por mulheres no Rio de Janeiro.

Utilizar as paredes e muros das cidades como suporte para registrar mensagens e imagens não é atividade recente. Desde as intervenções rupestres, encontradas nas cavernas de todos os continentes até o contemporâneo graffiti, escrever nos muros sempre esteve presente como ação criadora do homem. Com

um dos elementos constitutivos do movimento Hip-Hop ${ }^{5}$, o graffiti ${ }^{6}$ é a expressão plástica que tem como característica essencial o urbano e utiliza o espaço como suporte. Hoje ele está incorporado à rotina pública e abre discussão sobre a cidade, sua estética padronizada e o modo de vida no espaço urbano, recriando uma linguagem que confronta as normas visuais arquitetônicas e estabelece uma relação entre o homem e a paisagem.

A contradição que permeia essa prática artística advém, em grande medida, em nossa perspectiva, das tensões criadas no espaço público onde ela se desdobra.

\footnotetext{
${ }^{4}$ A experiência de mulheres grafiteiras na arte urbana no Rio de Janeiro. Tese de Doutorado apresentada ao curso de Pós Graduação em Serviço Social da Universidade do Estado do Rio de Janeiro, no ano de 2020.

${ }^{5} \mathrm{O}$ Hip-Hop se constitui de quatro elementos: o break (a dança de passos robóticos, quebrados e, quando realizada em equipe, sincronizados), o grafite (a pintura, normalmente feita com spray, aplicada nos muros da cidade), o DJ (o disc-jóquei) e o rapper (ou MC, mestre de cerimônias, aquele que canta ou declama as letras sobre as bases eletrônicas criadas e executadas ao vivo pelo DJ). A junção dos dois últimos elementos resulta na parte musical do hip hop: o rap (abreviação de rythym and poetry, ritmo e poesia, em inglês). Alguns integrantes do movimento consideram também um quinto elemento, a conscientização, que compreende principalmente a valorização da ascendência étnica negra, o conhecimento histórico da luta dos negros e de sua herança cultural, o combate ao preconceito racial, a recusa em aparecer na grande mídia e o menosprezo por valores como a ganância, a fama e o sucesso fácil. (ZENI, 2004, p. 4)

${ }^{6}$ A partir dele e de um cruzamento de técnicas e tendências, iniciaram, pós anos 90 , uma nova vertente que contempla diversas manifestações tais como o stencil (é uma técnica usada para aplicar uma ilustração ou símbolo tipográfico através do corte ou perfuração em papel ou acetato e tinta spray); o paste-up ou mais conhecido no Brasil como lambe-lambe (é uma modalidade de pôster street os pôsteres, geralmente são imagens gráficas feitos à mão ou impressos em papel fino ou colagens); ou a sticker art (etiquetas adesivas que podem ser escritas a mão ou produzidas por gráficas com suas tag ou marcas, geralmente coladas nos postes e placas das vias públicas) englobam dentre estas, outras formas e todo o tipo de arte que acontece na rua, seja ela teatro, estátuas humanas, performances, esculturas, instalações, entre outras.
} 
O proibido e o permitido, o público e o privado, o belo e o feio, as formas estéticas objetivadas ao consumo e as objetivadas à fruição. Por esta razão mesma, cabe destacar e refletir sobre as manifestações e práticas culturais como formas de resistências ao espaço normado do capital. O espaço homogeneizado, configurado pelo capital, vem desconstruindo as possibilidades de estabelecimento de uma diversidade social e cultural, assim como "a aniquilação de vestígios de outros modos de apropriação e uso do espaço social contribui para alienar distintos sujeitos sociais da possibilidade de apropriação, (re)conhecimento e encontro em suas cidades" (LIMONAD, BARBOSA, 2017, p. 15 - 17).

Pensar sobre a condição de gênero dentro de uma prática cultural que possui dimensões espaciais é refletir sobre as relações da mulher e de sua presença nos marcos da vida urbana. Este tipo de prática artística, assim como a história das mulheres, é constantemente apagada e invisibilizada e, por esta razão, cria um impacto significativo no cotidiano de suas vidas. Mesmo percebendo tensões, essa prática, em nosso ponto de vista, possibilita percepções sobre a cidade numa perspectiva de gênero que amplifica as experiências e as lutas das mulheres, reverberando temáticas e conflitos das questões de gênero historicamente presentes na sociedade contemporânea.

Essencialmente, pensar sobre gênero é pensar sobre a desconstrução de poder e das diferenças estabelecidas em um processo de dominação de homens sobre mulheres. Pensar sobre práticas artísticas elaboradas por mulheres é pensar em práticas que estabelecem um paradoxo com a cultura de dominação masculina; de outro modo, é pensar formas libertadoras sobre essa cultura. Demarcamos, desta forma, a relação entre arte e feminismo como uma relação que estabelece diálogos com questões trazidas sobre a condição e lutas femininas, tais como corpo, sexualidade e resgate de experiências e memórias. Localizamos, portanto, o feminismo como prática, logo, entendemos o graffiti feito por mulheres como uma prática feminista.

Atrelamos a essa perspectiva a afirmação de que ser uma mulher feminista é afirmar que os ideais de igualdade que representam o movimento permeiam vários âmbitos da vida cotidiana de mulheres. A prática feminista aqui é percebida, portanto, como um conjunto de ações que articuladas à prática artística metabolizam e potencializam de forma dupla e simultânea a finalidade do movimento feminista e a função social da arte. 
Desta forma, analisar o sujeito mulher artista na cidade é investir em uma frente de análise ainda pouco priorizada sobre as formas de luta e resistência estabelecidos pelo gênero em nossa sociabilidade. Acreditamos que a cultura se configura como uma prática de estabelecer e atribuir sentido e significado para as questões da realidade. Quando mulheres estabelecem esta conexão, mediadas pela arte e as questões e tensões de seu próprio gênero, criam possibilidades de um abalo e comprometimento no sentido positivo da desconstrução ideológica do papel socialmente atribuído à mulher.

Thompson (1981, p. 15) nos ajuda a refletir sobre a experiência de mulheres pois atenta-se para o fato de que "os seres sociais", através de sua capacidade de pensar, modificam seu cotidiano, quando refletem e agem sobre suas vidas e suas realidades. Dentro do campo da experiência, ele nos indica ser possível perceber os múltiplos caminhos que os sujeitos têm criado em seu cotidiano para resistir e tensionar a ordem de coisas estabelecidas.

Dentro das dimensões da vida cotidiana dos sujeitos não podemos diminuir e/ ou menosprezar certas práticas como meramente culturais ou corriqueiras. É necessário ultrapassar a aparência e perceber os movimentos que indiquem possibilidades de articulações mais amplas. Sobretudo, é necessário apontar esses movimentos através da experiência dos próprios sujeitos e de suas experiências em comum.

As experiências artísticas de mulheres através do graffiti nos despertaram o olhar para a análise das possibilidades da arte no resgate e construção de modos que transformam a vida cotidiana. Por este prisma carregamos de sentido político uma manifestação artística que vem sendo estigmatizada e realizamos uma investigação sobre as possibilidades pedagógicas que ampliam os horizontes de apreensão do real.

\section{Referências}

LEFEBVRE, Henri. A Revolução Urbana. Trad. Sérgio Martins. - 3a ed. - Belo Horizonte: Ed. UFMG, 2008.

LIMONAD, Ester; BARBOSA, Jorge Luiz Barbosa. "Why don't we do it in the road?" (Por que não o fazemos na rua?). Biblio3W. Revista Bibliográfica de Geografía y Ciencias Sociales, Barcelona, Universidad de Barcelona, vol. 22, no 1.197, abril de 2017. 
THOMPSON, Edward Palmer. A miséria da teoria ou um planetário de erros. Rio de Janeiro: Zahar, 1981.

VÁSQUEZ, Adolfo Sánches. As ideias estéticas de Marx. Tradução de Carlos Nelson Coutinho. 3. ed. - São Paulo: Expressão Popular, 2010.

ZENI, Bruno. O negro drama do rap: entre a lei do cão e a lei da selva. Estudos Avançados, São Paulo, vol.18, n.50, p.225-241, jan-abril de 2004.

\section{Escuta as Manas:}

[...] As mulheres estão começando a se fortalecer e pintando entre elas mesmas, então a gente não vê mais necessidade de chegar sozinha no mutirão, por exemplo. E enfrentar muita coisa desnecessária de homem. Então a gente vai acompanhada nos mutirões, a gente faz os nossos próprios mutirões, a gente consegue ter um ambiente mais seguro e mais confortável pra gente trabalhar a partir daí (F., 2019).

[...] Mas eu acho que a contribuição é essa, para as mulheres, a gente consegue falar mais sobre as coisas quando a gente tá pintando, sabe? Não é só assim, ah eu vou lá pintar. Eu vou lá, pintar com as minhas manas, trocar uma ideia, sabe? É outra vibe [...] Tanto que a gente criou muitas crews, né? Crews é invenção das mulheres. Além da questão da segurança, né? Porque a gente queria grafitar com segurança, elas foram criadas para a gente fazer grupo de mulheres para pintar juntas, porque a gente não tinha segurança de fazer sozinha, como os caras fazem. Mas também para essa coisa da gente tá junto, dialogar junto, uma complementar o desenho da outra. É outra pegada (S., A. 2019).

Acho que o graffiti também tem isso, sabe? De colocar mensagem, sabe? [...] então, a gente botou ali 180, a gente botou a nossa arte, uma frase da música da Elza Soares. Então, assim, às vezes uma amiga que tá sofrendo abuso e tipo tem vergonha, e não quer contar para ninguém. Ela passa ali vê aquela parada e fala: "[...] Esse número eu vou gravar!". E de repente, algum momento ela pode precisar. Ou, às vezes, você tá num dia horrível, mano... horrível! Aí tu passa ali na Rua do Catete, tem um graffiti da Panmela escrito: "Toda mulher é linda!". [...] Então, eu acho que de alguma forma ele pode influenciar e eu acho que esse é o papel da arte também, questionamento sempre (V., 2019).

Então, o graffiti ele faz isso, ele faz a mulher perder o medo, faz a mulher invadir os espaços [...]. E o graffiti faz você se deslocar na sua cidade, isso é importante. $O$ grafite faz você sentir segurança na irmandade de uma outra mulher, cara. (C., 2019). 


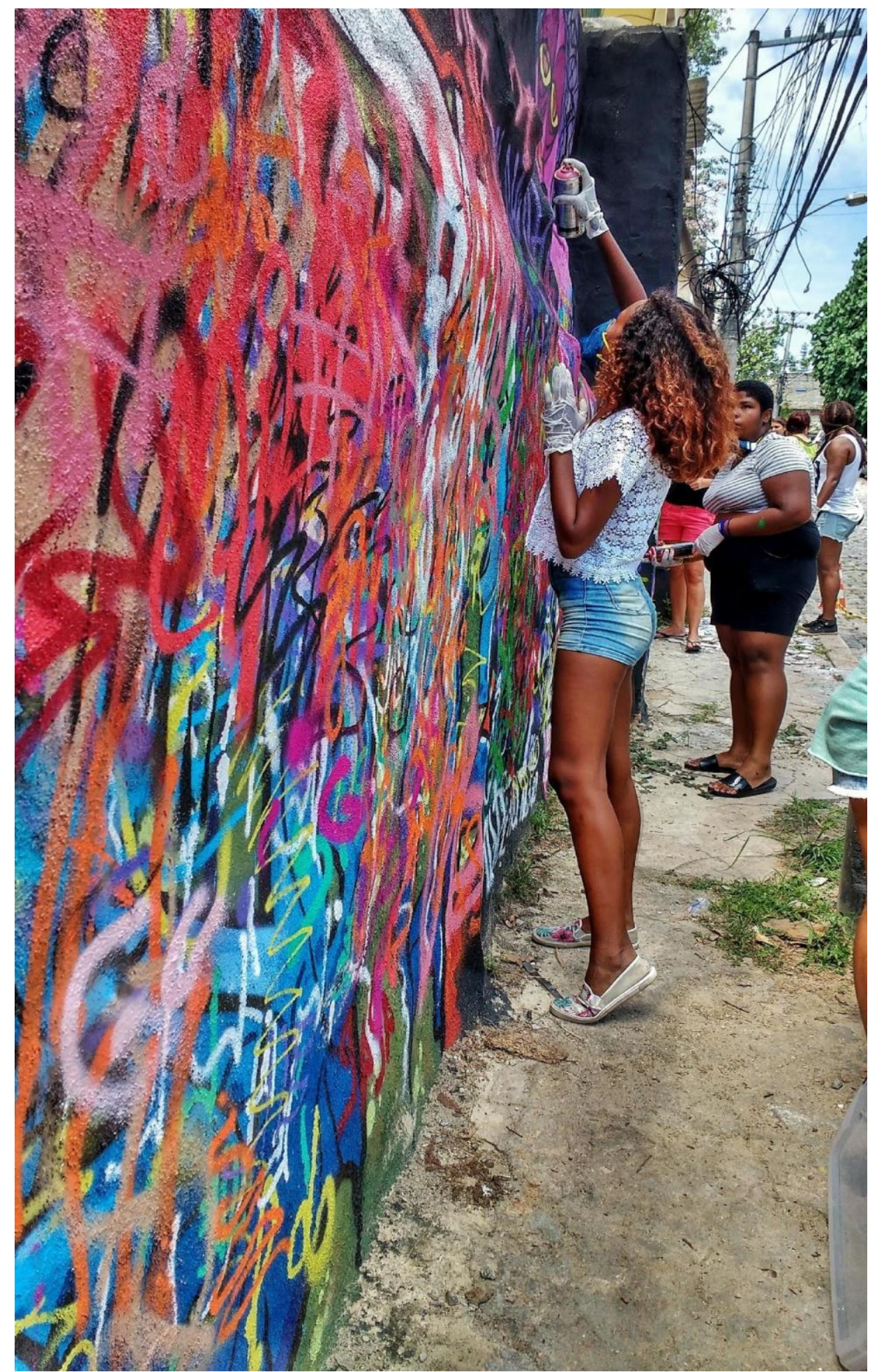

Foto: Alcançando Cores

Autor: Priscila Castro, Rede Nami - Tavares Bastos -RJ, março de 2017. 


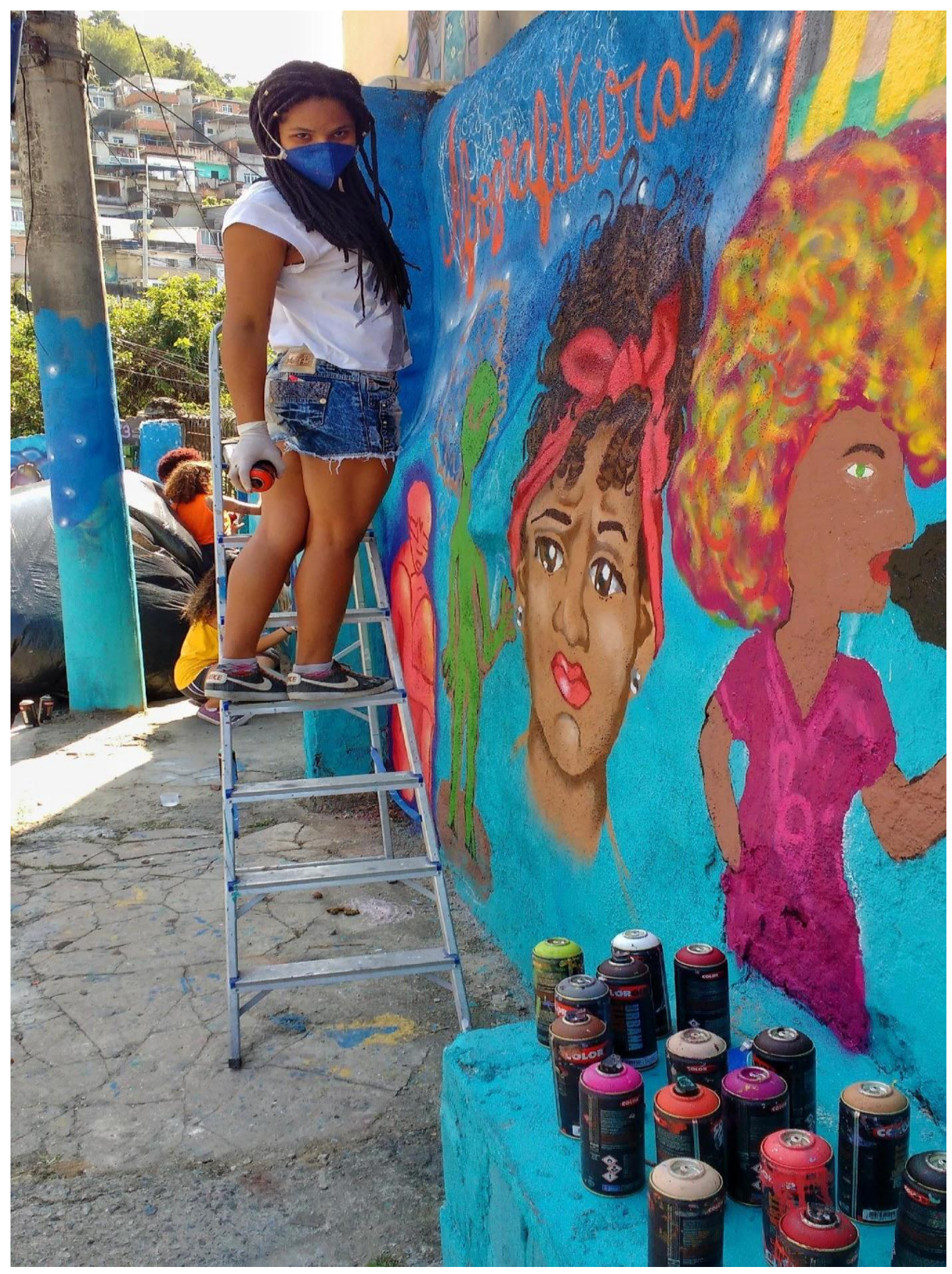

Foto: No topo

Autor: Priscila Castro, Rede Nami - Tavares Bastos - RJ, agosto 2017. 


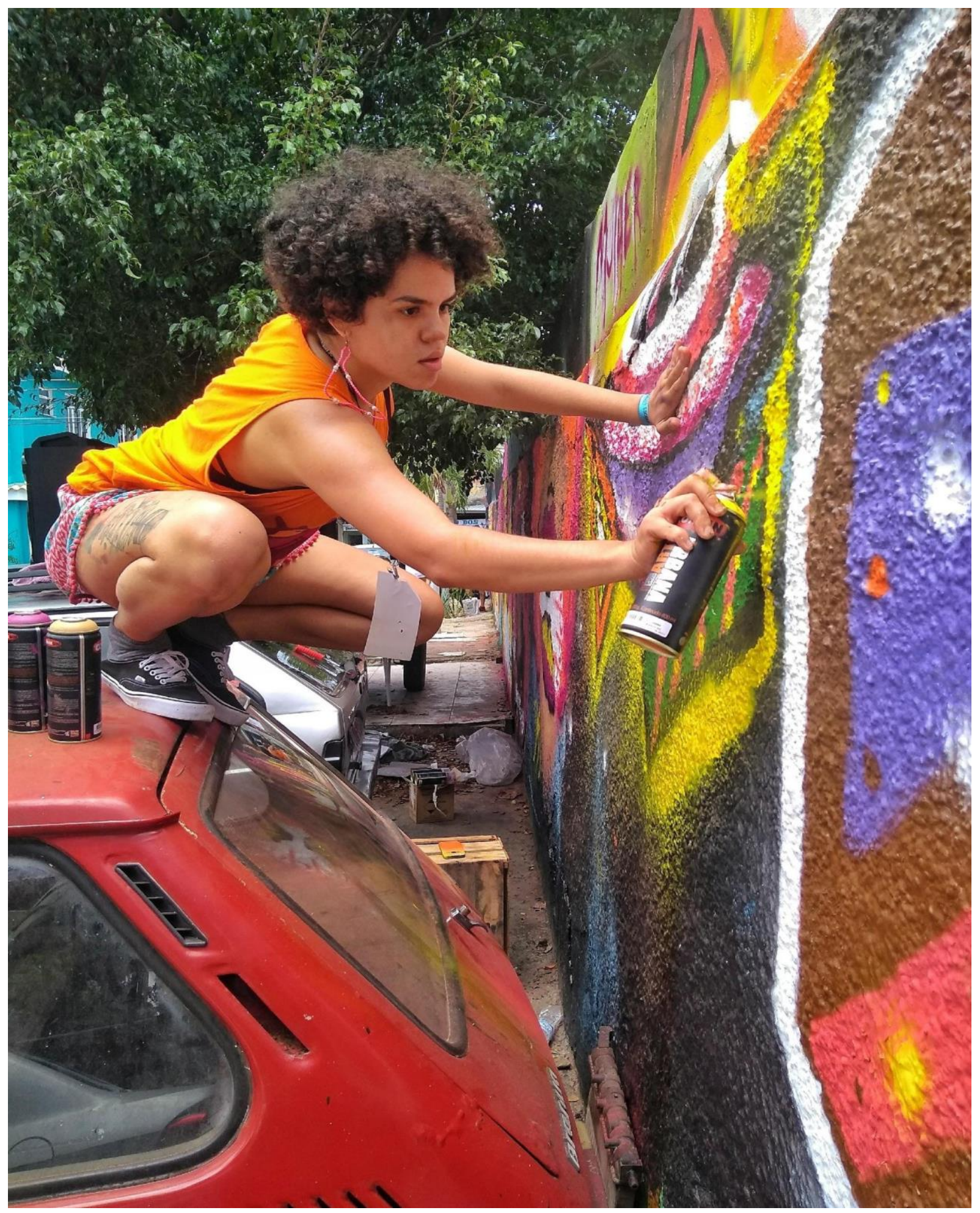

Foto: Não tem Obstáculo

Autor: Priscila Castro, Meeting of Favela - Duque de Caxias - RJ, dezembro de 2017. 


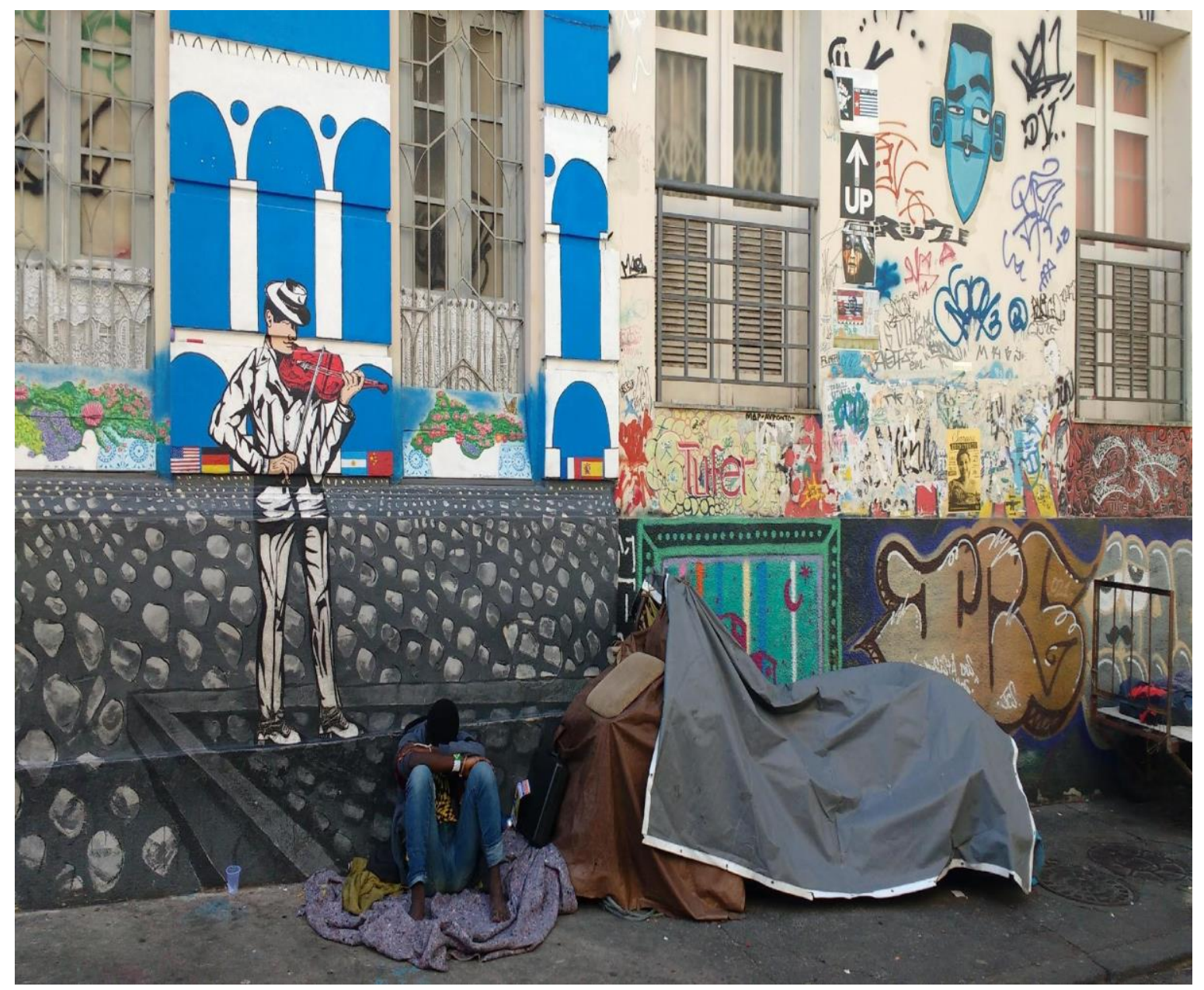

Foto: Enxergar

Autor: Priscila Castro, Lapa - RJ, agosto de 2017. 


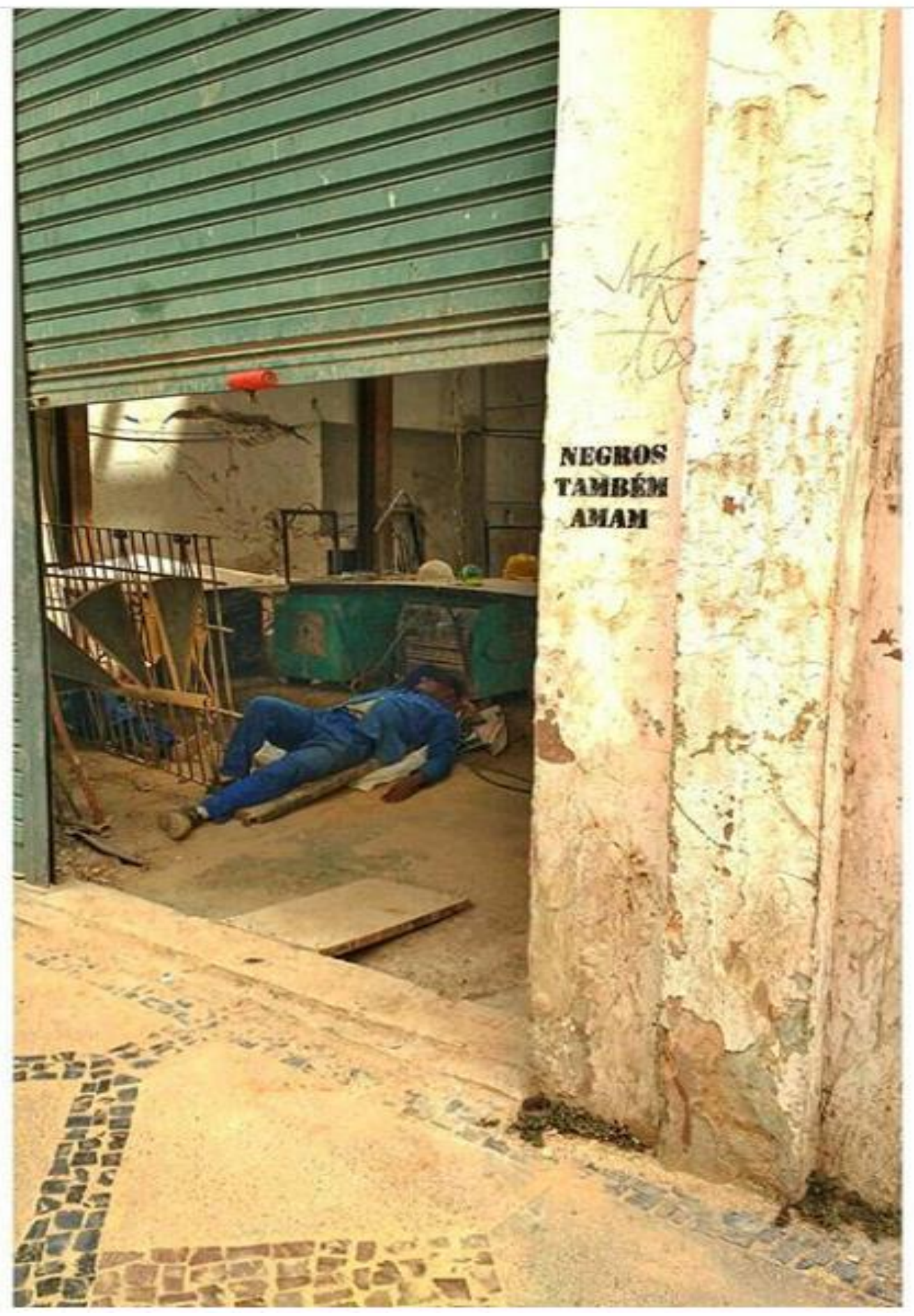

Foto: Amam e Descansam

Autor: Priscila Castro, Lapa - RJ, outubro de 2016. 


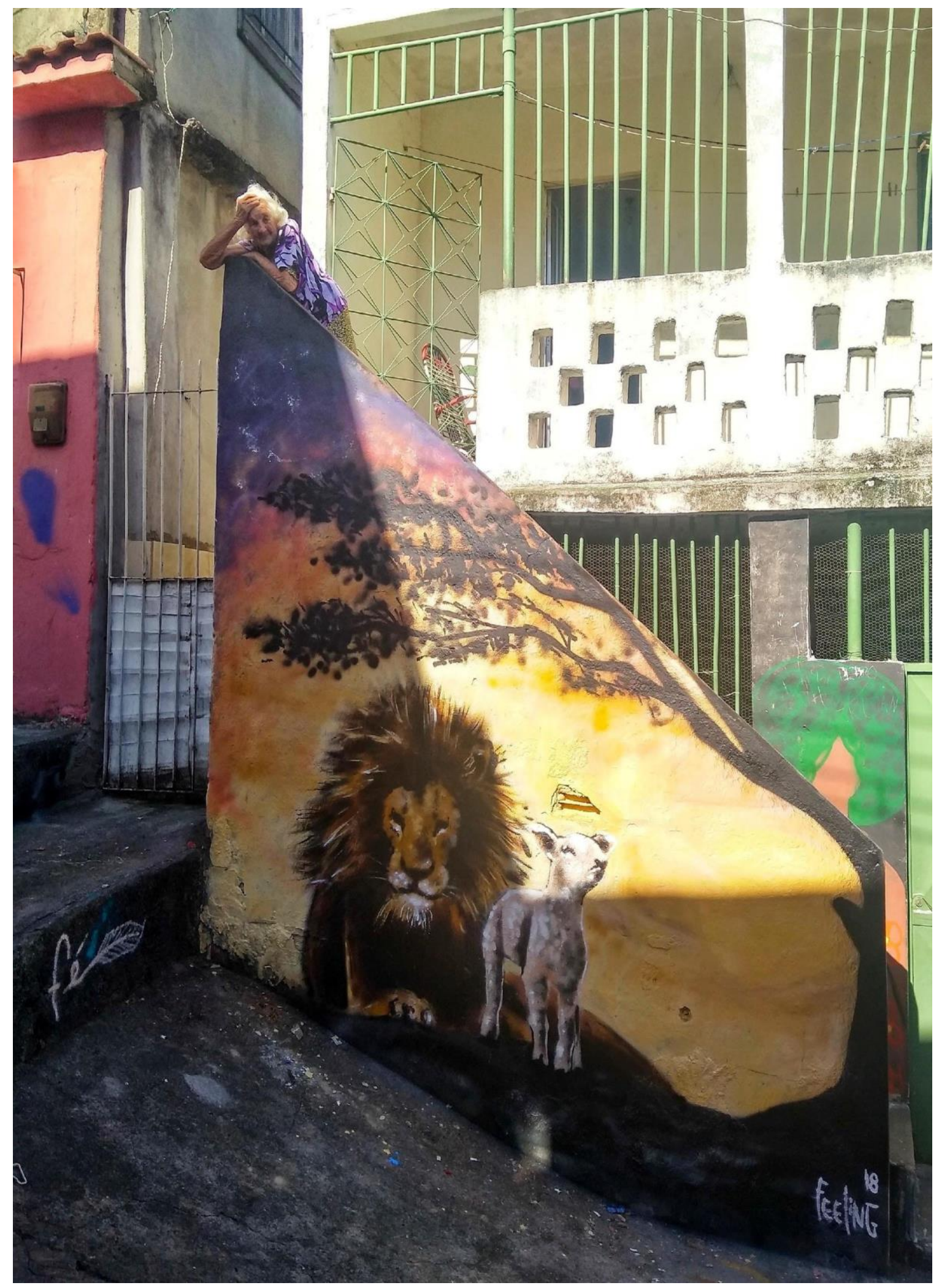

Foto: Sereno Rugido

Autor: Priscila Castro, Meeting of Favela - Duque de Caxias - RJ, dezembro de 2018. 


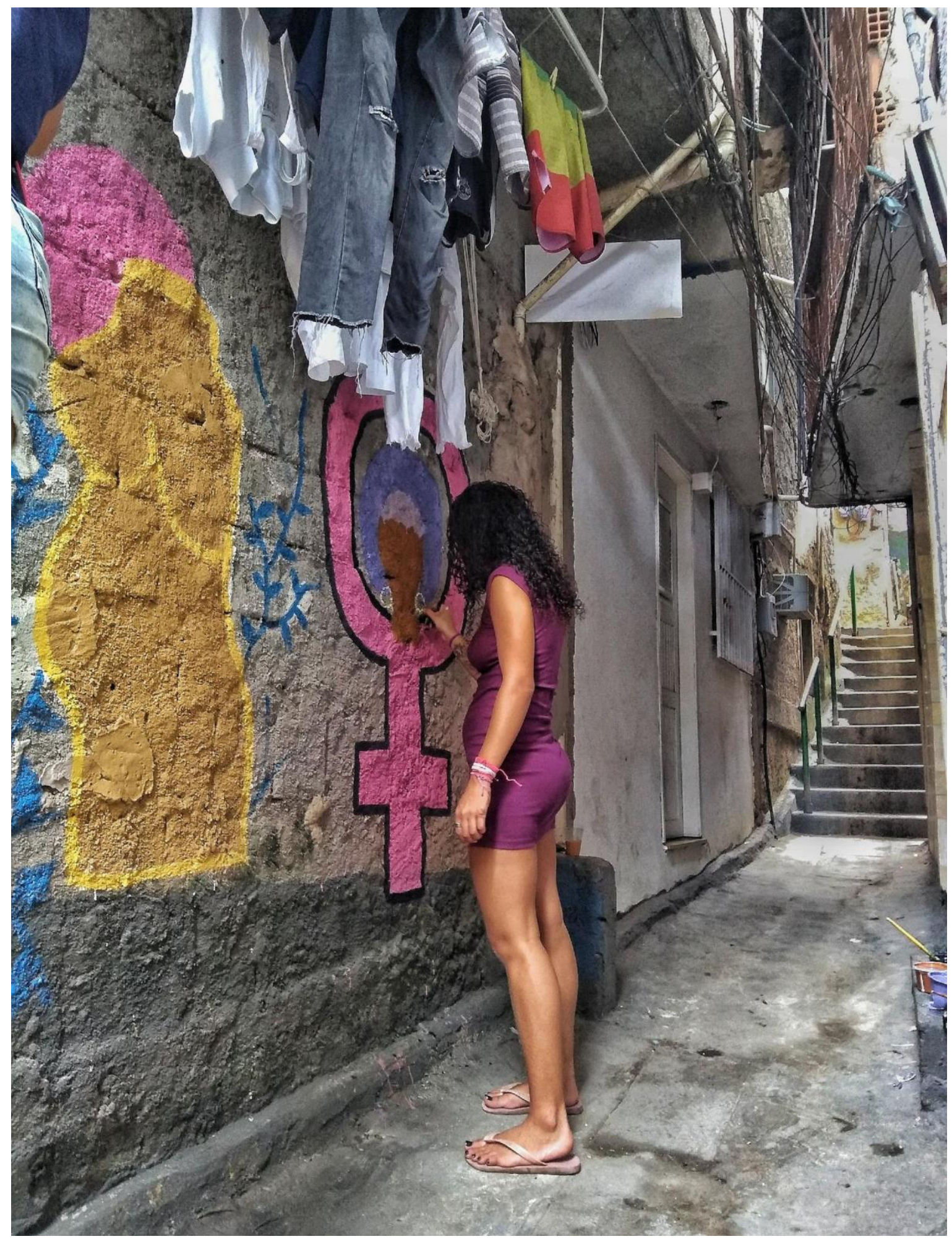

Foto: Spray de Vênus

Autor: Priscila Castro, Tavares Bastos - RJ, maio de 2018. 


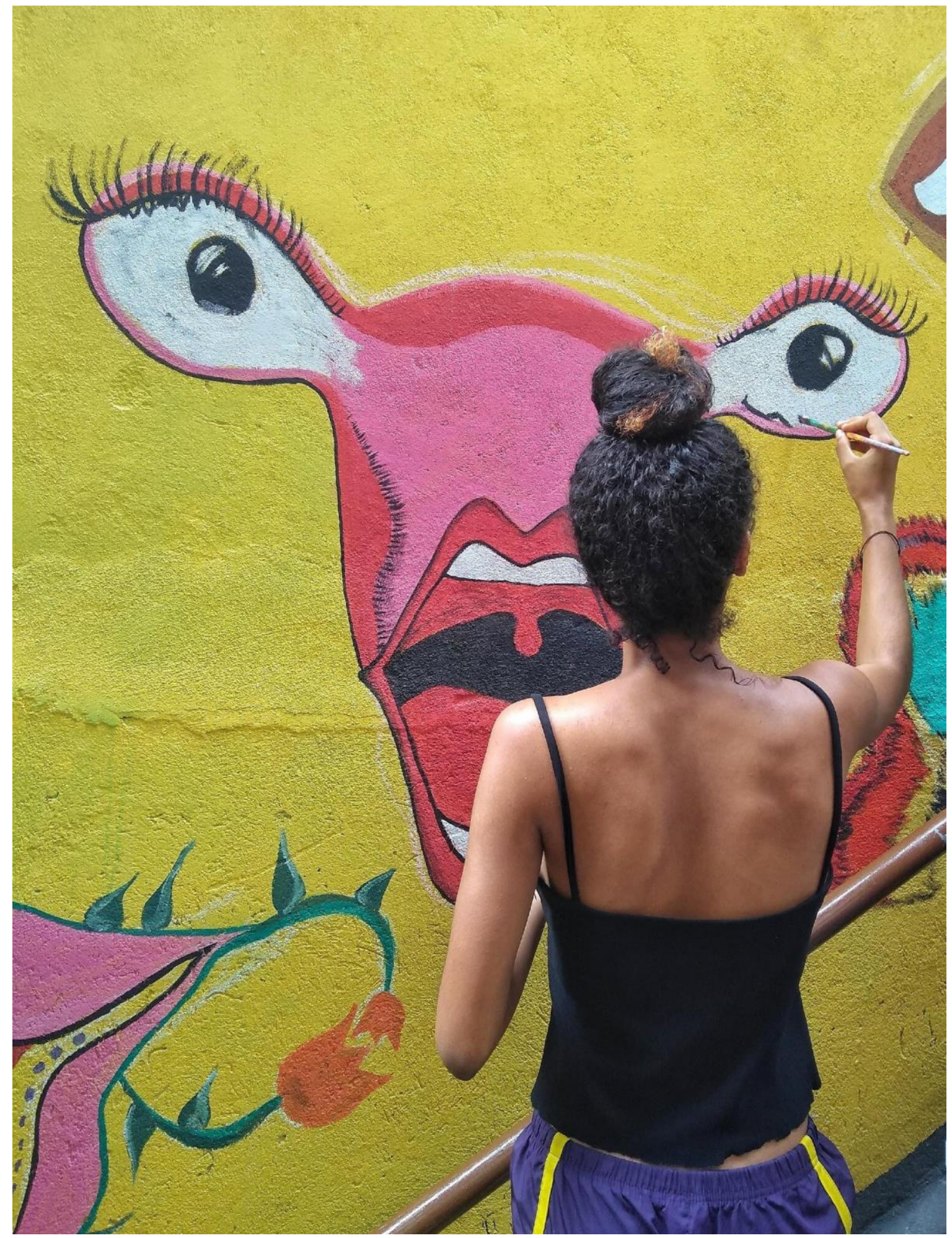

Foto: Entre Ovários

Autor: Priscila Castro, Tavares Bastos - RJ, maio de 2018. 


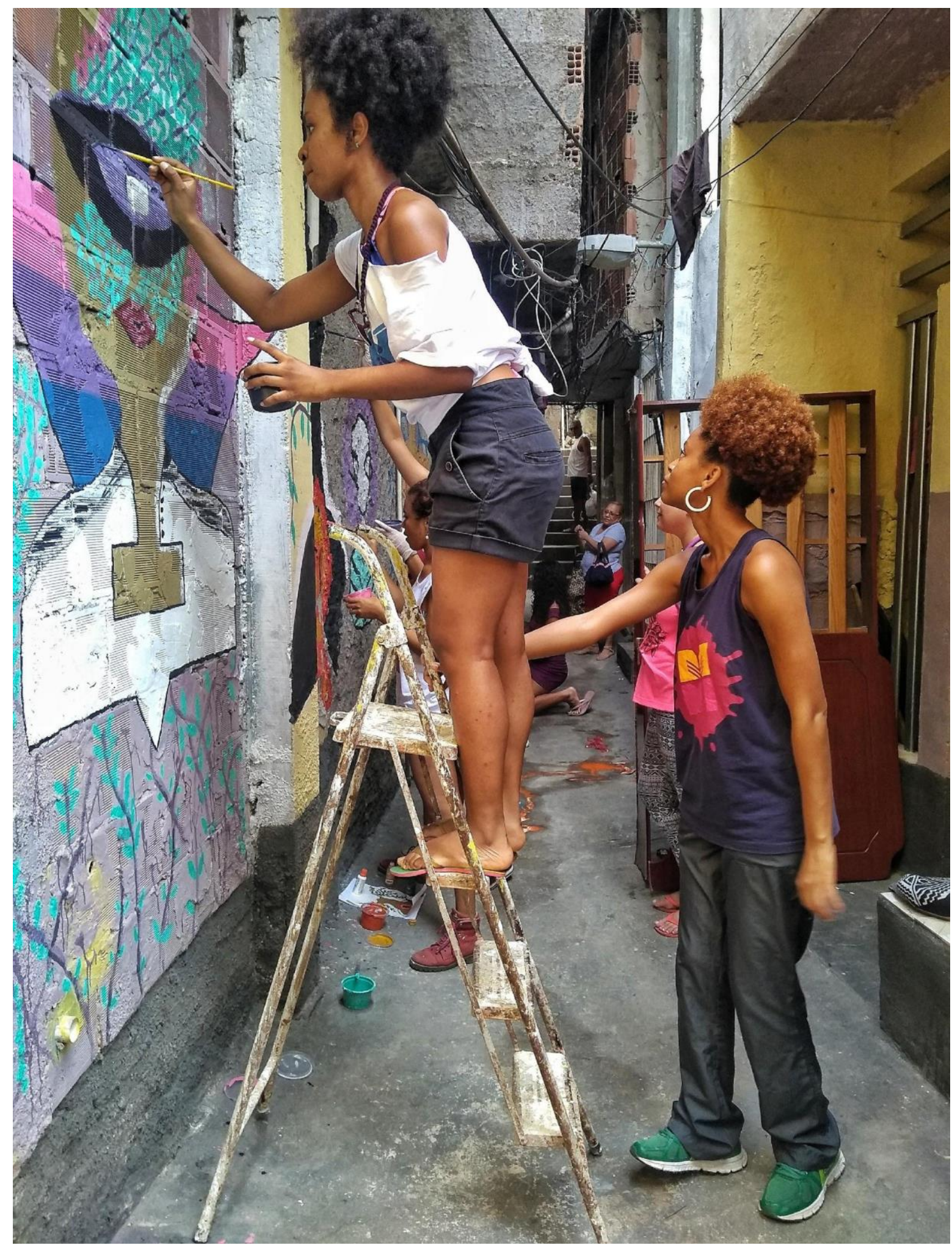

Foto: Apoio

Autor: Priscila Castro, Tavares Bastos - RJ, maio de 2018. 


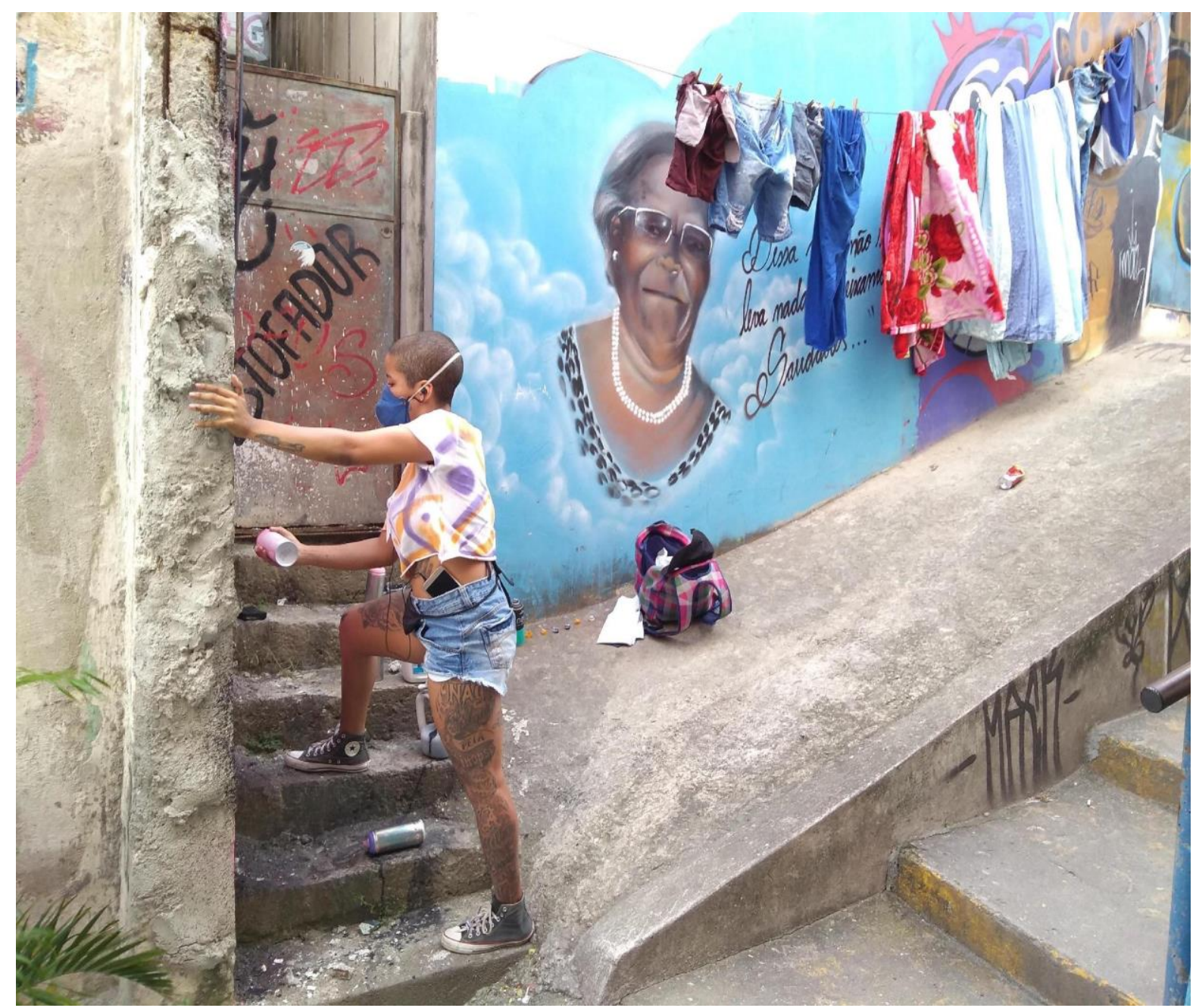

Foto: O vento veste cores

Autor: Priscila Castro, Meeting of Favela - Duque de Caxias - RJ, dezembro de 2019. 


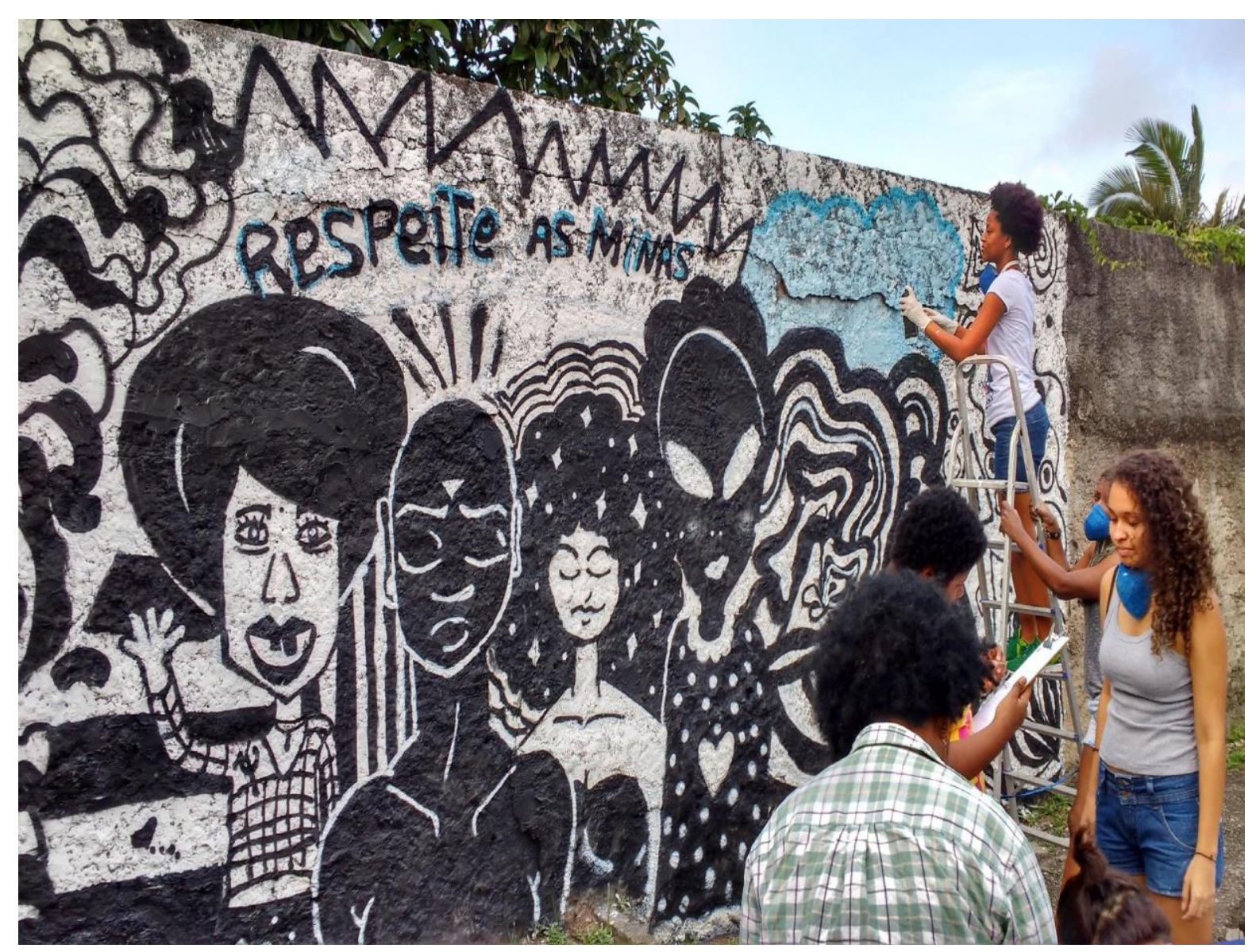

Foto: Aprendam

Autor: Priscila Castro, Tavares Bastos - RJ, julho 2017. 